REVIEW

\title{
Outcomes of fundoplication: causes for concern, newer options
}

\section{E Hassall}

Arch Dis Child 2005;90:1047-1052. doi: 10.1136/adc.2004.069674

Antireflux surgery has been a mainstay of treatment for gastro-oesophageal reflux disease in children for some 40 years. In recent years, enthusiasm for antireflux surgery seems only to have increased, despite its often poor outcome, and the availability of highly effective medical therapy in the form of proton pump inhibitors (PPIs). Reports show that many children undergo surgery without reflux disease as the demonstrable cause of their symptoms/signs, and without evidence of having failed optimised medical management. Very few studies report objective testing postoperatively-those that do show high rates of failure within the first 1-3 years following surgery. Treatment with PPIs is an effective and safe alternative to surgery in many cases.

Correspondence to: Dr E Hassall, Professor of Pediatrics, Division of Pediatric

Gastroenterology, BC Children's Hospital/ University of British Columbia, 4480 Oak St, Vancouver, BC V6H 3V4 Canada; ehassall@cw.bc. $\mathrm{ca}$

Accepted 25 May 2005

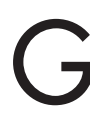
astro-oesophageal reflux (GOR) refers to the passage of gastric contents into the oesophagus-it is often physiological, as in many infants, and occurs postprandially in adults and children. In contrast, GO reflux disease (GORD) is present when reflux is pathologic - that is, a complication of reflux is present (box 1). In infants, GOR and GORD both most commonly present with regurgitation or vomiting or "spitting up". ${ }^{2}$ These symptoms occur daily in up to $67 \%$ of otherwise healthy and thriving infants 4-5 months of age, declining to $21 \%$ by age $6-7$ months, and to less than $5 \%$ by 12 months. ${ }^{1}$ Thus, in the great majority of infants, the natural history of reflux is of selfresolution without sequelae.

Complications of reflux include oesophagitis, stricture, Barrett's oesophagus, and extra-oesophageal conditions (box 1). While many complications of GORD are more prevalent in adults than in children, likely due to the longevity of pathologic reflux, they do occur in children. ${ }^{3-6}$ Vomiting is a less prevalent symptom of GORD in children beyond infancy. ${ }^{2}$

For GORD that is severe and/or chronic, the major treatment options are medical treatment with proton pump inhibitors (PPIs) or antireflux surgery.

\section{CHILDREN AT RISK FOR SEVERE REFLUX}

Children with certain underlying disorders are at the greatest risk for severe GORD. These include those with neurological impairment (NI) (that is, any major neuromotor impairment such as cerebral palsy or syndromes), those with repaired oesophageal atresia $(O A)$ or congenital diaphragmatic hernia, and those with chronic lung disease. Severe GORD may also occur in otherwise healthy children (those without any underlying systemic disorder), especially those with a hiatal hernia, or perhaps acid hypersecretion.

\section{Mechanisms of reflux}

These are described in detail elsewhere, ${ }^{6-13}$ but explained in brief as follows. Gastrointestinal dysmotility is a major pro-reflux factor in some conditions, the term "dysmotility" referring to the absence of normal neuromuscular function of the GI tract. Normal individuals have some GO reflux, especially postprandially, but by reflex propagated peristalsis, refluxate is promptly cleared from the oesophagus back into the stomach. In the neurologically impaired (NI), the oesophagus is poorly motile, sometimes flaccid, and refluxate is not promptly cleared, leading to prolonged acid contact time and damage-that is, oesophagitis, which further impairs motor function. A prevalent mechanism of pathologic reflux is the presence of inappropriate transient lower oesophageal sphincter relaxations.

In the normal stomach, neuromuscular mechanisms effect receptive relaxation of the fundus and body when food enters, and control mechanical digestion and gastric emptying. In NI, these functions are often impaired, with delayed gastric emptying, increased intragastric pressure, and reflux into the oesophagus. Similarly, dysmotility of the duodenum results in reflux of duodenal contents into the stomach, which then may be refluxed into the oesophagus along with gastric contents. Children with NI also have many other pro-reflux factors.

In oesophageal atresia (OA), although anatomic continuity is surgically established in the first days of life, the oesophagus is congenitally abnormally innervated, thus it is dysmotile, never having functioned with normal peristalsis in utero. Hiatal hernia is also often present in OA.

In chronic lung disease, chronic cough and negative intrathoracic presssure promote reflux.

In hiatal hernia, a number of mechanisms come into play, the major one being exposure of the lower oesophageal sphincter zone to negative intrathoracic pressure. ${ }^{13}$

Abbreviations: $\mathrm{GOR}$, gastro-oesophageal reflux; GORD, gastro-oesophageal reflux disease; $\mathrm{H}_{2} \mathrm{RA}$, histamine-2 receptor antagonists; LNF, laparoscopic Nissen fundoplication; NI, neurological impairment; $\mathrm{OA}$, oesophageal atresia; ONF, open Nissen fundoplication; $\mathrm{PPI}$, proton pump inhibitor 
Box 1: GORD: complications of GOR in children

Oesophageal

- Oesophagitis: erosive/non-erosive

- Stricture

- Barrett's oesophagus

- Adenocarcinoma

Systemic

- Blood loss anaemia

- Failure-to-thrive

- "Feeding difficulties"

- Compromised quality of life

Extra-oesophageal

- Dental erosions

- Pulmonary

- Non-seasonal asthma

- Chronic cough

- Recurrent pneumonias

- Bronchiectasis

- Ear, nose, and throat

- Laryngitis, hoarseness

- Globus

- Sore throat

- Recurrent otitis media, sinusitis

\section{TESTS}

- Barium upper GI contrast study is a poor test to determine or rule out pathologic reflux, with many false positives and negatives. ${ }^{4}{ }^{7}$ It is generally not a functional study. Rather, it is best used as a "road map", to rule out anatomic abnormalities, such as mechanical obstruction, intestinal malrotation, oesophageal stricture, achalasia, or a fundoplication ("wrap") that has slipped into the chest.

- Upper GI endoscopy with biopsies is the only test that can definitively diagnose reflux oesophagitis and distinguish it from the many other causes of oesophagitis and upper GI conditions that may cause similar presenting symptoms, such as peptic ulcer diseases or gastritis/gastropathy. ${ }^{4}{ }^{14}$

- 24 hour intra-oesophageal $p H$ study is said to be the gold standard for quantitating acid reflux. It is not routinely indicated in children who are vomiting, nor when reflux oesophagitis has been diagnosed. It may be useful to determine whether acid reflux is present, such as in undiagnosed chest pain, postoperative situations, suspected GORD related respiratory disease, to distinguish between reflux and non-reflux associated oesophageal disease, or to titrate medication doses. ${ }^{4}$

- Scintiscans with radio-labelled apple juice or milk are largely out of favour, except in the relatively rare circumstance of determining reflux associated aspiration. ${ }^{4}$

- Gastric emptying studies may be used to determine if delayed gastric emptying is an underlying factor in a GORD patient. $^{4}$

- Oesophageal manometry measures lower oesophageal sphincter pressure and ability to relax, as well as oesophageal peristalsis. It is not routinely used in the investigation of GORD. ${ }^{4}$

- Intraluminal impedance measurement detects non-acid reflux, or "volume reflux", and is in a relatively early stage of use in children.
While barium study is useful to identify a slipped wrap or stricture, endoscopy and intra-oesophageal $\mathrm{pH}$ and are required to diagnose oesophagitis and acid reflux and respectively.

\section{TREATMENT GOALS}

These are: relief of symptoms, mucosal healing, treatment of complications, prevention of complications, and maintenance of remission.

\section{TREATMENT OPTIONS}

"Lifestyle changes" (weight loss, dietary changes), histamine-2 receptor antagonists $\left(\mathrm{H}_{2} \mathrm{RA}\right)$, or prokinetic agents may be sufficient for symptom relief in "minor league" reflux. Empiric trials of therapy, including with PPIs, are often useful, especially in patients over 8-10 years of age, with mild to moderate symptoms that are typical for reflux, and no alarm symptoms of bleeding, weight loss, or dysphagia. However, such trials should be of limited duration, perhaps 612 weeks, and the child should be referred for subspecialist evaluation if symptoms are not alleviated, or recur off treatment. Chronic therapy should not be continued indefinitely without an endoscopic diagnosis. ${ }^{4}{ }^{14}$

For children with severe and/or chronic, relapsing GORDthat is, with a complication ("Premier League reflux"), the management equation becomes one of long term PPI therapy versus antireflux surgery.

\section{ANTIREFLUX SURGERY}

Until the early 1990s or so, antireflux surgery was the mainstay of treatment for severe GORD in children, ${ }^{15-17}$ as there was no real medical alternative; the efficacy of $\mathrm{H}_{2} \mathrm{RAs}$ and prokinetics was simply not up to the task. In contrast, PPIs, are highly efficacious for severe GORD, if properly used. Yet, despite the availability and proven efficacy of PPIs over the last some 15 years, and the high morbidity and failure rates of antireflux surgery, ${ }^{18-41}$ the operative approach remains ever more widely used in children. Failed surgery is often treated with a second or third operation. In North America (and perhaps elsewhere), fundoplication is among the most commonly performed of operations in paediatric surgery, with rates of hospitalisation and operation apparently increasing, especially under 2 years of age. ${ }^{39}{ }^{40}$ One US study showed that $14 \%$ of patients hospitalised for GORD underwent fundoplication without consultation with a gastroenterologist or any form of diagnostic evaluation to prove that GORD was present or assess its severity. ${ }^{39}$ The majority of children appear come to surgery with often only a barium study; less than $25 \%$ undergo basic objective testing

Table 1 Intraoperative findings during 179 redo operations after a failed primary minimally invasive antireflux procedure in adults, 1993-2000

\begin{tabular}{llr}
\hline Finding & $\mathbf{n}$ & $\%^{*}$ \\
\hline Wrap herniation & 65 & 36.3 \\
Tight wrap & 30 & 16.8 \\
Slipped wrap & 25 & 14.0 \\
Disrupted wrap & 23 & 12.8 \\
Malpositioned wrap & 19 & 10.6 \\
Oesophageal stricture & 10 & 5.0 \\
Loose wrap & 9 & 2.2 \\
Other & 4 & 5.6 \\
\hline
\end{tabular}

Information obtained from eight papers.

*Rates do not add up to $100 \%$, because some patients had more than one finding.

Reprinted from: Carlson MA, Frantzides CT. Complications and results of primary minimally invasive antireflux procedures: a review of 10,735 reported cases (table 1). J Am Coll Surg 2001;193:428-39. Copyright 2001 with permission from American College of Surgeons. 


\section{Box 2: Early complications of antireflux surgery*}

- Oesophageal perforation

- Gastric perforation

- Haemorrhage

- Splenic injury requiring splenectomy

- Intraoperative cardiac arrest

- Necrotising enterocolitis

- Leakage of gastrostomy requiring reoperation

- Intestinal obstruction due to adhesions

- Protracted ileus

- Gas bloat syndrome

- Retching

- Dumping syndrome

- Gastrostomy site infection

- Wound sepsis

- Respiratory complications

- Oesophageal pseudo-obstruction

- Sepsis, multi-organ system failure

- Death

${ }^{*}$ Compiled from references 18-24, 26, 28, 29

\section{Reported outcomes}

Perioperative complications are listed in box 2. The frequency of complications is greater in NI children than in those without $\mathrm{NI}^{20}$ and after a second or subsequent antireflux operation. ${ }^{21}$

A more detailed analysis of some studies is given elsewhere. ${ }^{11}$ As indicated, the problems with surgery occur especially in children with certain underlying conditions. For example, compared with neurologically normal (NN) children, neurologically impaired (NI) children had more than twice the complication rate, three times the morbidity rate, and four times the antireflux surgery reoperation rate, all within a mean follow up of only 1.6 years. ${ }^{20}$ In another study, ${ }^{22}$ over $30 \%$ of NI children had major complications or died within 30 days of surgery; within a mean follow up of 3.5 years, $25 \%$ had documented operative failure, and overall $71 \%$ had return of one or more preoperative symptoms of GOR within one year of surgery. In children with repaired oesophageal atresia, only $40 \%$ had an "excellent result" at 5 years, including those requiring reoperation; ${ }^{18} 27$ those with OA undergoing antireflux surgery in early infancy had a high rate of surgical failure and mortality. ${ }^{32}$

Recurrent GOR after antireflux surgery in children with NI or OA may not be obvious, ${ }^{23} 2746$ and detection often requires a high index of suspicion, repeated evaluation over time, and use of more than one test.

Children without underlying disorders may also have poor outcome rates. In one of the few reports of objective testing postoperatively that included "normal" children, ${ }^{33} 53$ children who had had laparoscopic Thal fundoplication had endoscopy and intra-oesophageal $\mathrm{pH}$ studies a mean of 10 months (1-35) postoperatively. Of the 18 "normal" children only $67 \%$ had "no complaints", and almost one third had objective evidence of operative failure. Of the $37 \mathrm{NI}$ children, 39\% had objective evidence of operative failure.

In a recent study from one of the largest children's hospitals in the USA, nearly two thirds of 176 children who had fundoplication continue to have symptoms of reflux, or receive medical therapy for such ${ }^{38}$ In another study, from the UK, fundoplication in early infancy (median 9 weeks of age) was found to be unsuccessful in a high proportion of patients. ${ }^{32}$ This group had other risk factors, 56 of 66 patients having associated anomalies, and children with OA did especially poorly.

Other surgical reports paint a rosier picture. In a textbook chapter, ${ }^{25} 1125$ patients were reported to have had fundoplications between 1973 and 1990. It was stated that only 2\% developed recurrent GOR. Claims was made that "fundoplication in an infant or child can be anticipated to last indefinitely" and that "fundoplications hold up during the period of growth and development of the child". In support of these assertions were quoted three articles, none of which used objective postoperative testing.

One much cited report from seven major centres in the USA deserves a close look. In a review of over 7000 patient charts, ${ }^{27}$ authors reported "good to excellent long term results" in $94 \%$ of neurologically normal children, and $85 \%$ of NI children. However, the subjective terms "good" and "excellent" were not defined; other possibilities (for example, "poor"/"very poor", etc) were not offered. There were no objective endpoints or outcome measures. The study instrument consisted of a questionnaire filled out at each of seven centres, up to 20 years (mean 7.3 years) after antireflux surgery. The study instrument with specific questions and wording was not presented. "Long term" referred to when the questionnaire was completed rather than when the patient was last seen and objectively evaluated. The report was seriously flawed in its methodology, and therefore misleading in its conclusions. 
Of particular concern in that study is that $40 \%$ of patients underwent surgery below 1 year of age. In many infants presenting under age 12 months, symptoms and signs will resolve with temporising or optimised medical treatment, and remain so when treatment is stopped; after all, GOR is often transient in infants. In contrast, GO reflux disease (GORD) - that is, GOR with a complication, a chronic/ recurrent disorder, was shown in only a minority of patients in that study; only $25 \%$ of the patients overall underwent upper GI endoscopy and only $12 \%$ had oesophagitis. Thus, the indications for surgery were unclear in a large number of patients. Similar concerns apply to other reports, in which some $50 \%$ of cases are under 1 year of age. ${ }^{47}$

Outcomes of antireflux surgery have been more carefully studied in adults than in children. In one study, ${ }^{48}$ at a mean of $20( \pm 10)$ months after surgery, only $61 \%$ of adults were satisfied with their outcome; $32 \%$ were taking medications for heartburn, $11 \%$ required oesophageal dilatation, and $7 \%$ had repeat surgery. This study found that substantial numbers of patients undergo fundoplication for questionable reasons. In addition, even when patients do not have typical reflux symptoms postoperatively, after surgery new symptoms developed in $67 \%$ of patients, ${ }^{49}$ including excessive gas, abdominal bloating, increased flatus, difficulty with eructation and vomiting, and dysphagia. ${ }^{48-50}$

In a large controlled study, Spechler et al found at 7 years follow up after antireflux surgery, $62 \%$ of adults were taking PPIs for reflux symptoms. ${ }^{50}$ Another study showed a similarly high surgical failure rate. ${ }^{51}$

\section{Laparoscopic versus open fundoplication}

Open Nissen fundoplication (ONF) has largely been replaced by laparoscopic Nissen fundoplication (LNF) as the preferred operative approach. The main benefits of LNF in adults and children are shorter hospital stays, and fewer perioperative problems such as prolonged ileus and respiratory infections. ${ }^{41-43}{ }^{52-55}$ However, the morbidity and mortality of LNF are particularly sensitive to the level of experience of the surgeon/surgical unit, and LNF has a steep learning curve. $^{41-43}$ 52-55 This aside, even with experienced surgeons, LNF is attended by as high a failure rate as open surgery in adults. $^{42}$

One study in which patients were randomised to ONF versus LNF was halted because of the much higher incidence of disabling dysphagia in LNF. ${ }^{45}$ In children, those with 1-3 comorbidities had a probability of reoperation of $18-24 \%$ after LNF, compared with $6-16 \%$ for ONF; time to reoperation with LNF was 11 months, versus 17 months for ONF. ${ }^{41}$ This study excluded children with oesophageal atresia, and did not routinely use objective testing pos-operatively, so the actual failure rates are likely higher.

Death related to open or laparoscopic surgery also occurs. In adults, the mortality of the index (that is, first) operation is between 1 in 1000 to 1 in $330 .{ }^{43} 5253$ In one study, of some 5500 operations in adults, ${ }^{53}$ there were 43 fatal or life threatening complications (an overall prevalence of $0.8 \%$, $0.3 \%$ of which were fatal), more with laparoscopic than open surgery. In children, those with underlying disorders, such as NI, are at substantially greater risk for surgical mortality, ${ }^{20}$ as are those in early infancy. ${ }^{32}$

\section{PROTON PUMP INHIBITOR THERAPY}

Studies in adults have repeatedly shown that treatment with PPI therapy results in higher and faster rates of oesophagitis healing compared with an $\mathrm{H}_{2}$ RA. ${ }^{56} 57$

The superior efficacy of healing by PPIs is largely due to their ability to maintain intragastric $\mathrm{pH}$ at or above 4 for longer periods of time and to inhibit meal induced acid secretion; ${ }^{58}$ in contrast, $\mathrm{H}_{2}$ RAs do not inhibit the latter. The
pH effect of PPIs affords symptom relief and heals oesophagitis, also resulting in less reflex vomiting. The potent suppression of acid secretion by PPIs also results in decrease of 24 hour intragastric volumes, thereby facilitating gastric emptying and decreasing volume reflux. ${ }^{59}$ In addition, the effect of PPIs does not diminish with time, in contrast to the tachyphylaxis that may occur with $\mathrm{H}_{2}$ RAs. ${ }^{60}{ }^{61}$

As in adults, in children, PPIs are highly efficacious and safe for the treatment of GORD related symptoms and signs, including the most severe degrees of reflux oesophagitis, with rates of symptom relief and cure of oesophagitis above $90 \%{ }^{62-67}$ At present, in the USA, only two PPIs are approved for use in children, omeprazole (Losec, Prilosec) and lansoprazole (Prevacid). While regulations vary between countries, to the best of the author's knowledge, no PPIs are approved for use below l year of age.

Whereas the safety of omeprazole has been shown in adults for up to 11 years' continuous use, ${ }^{68}$ safety data for that duration of use in children are not available as yet. Studies do show efficacy and safety of PPI use in children up to 3 months for healing by omeprazole or lansoprazole. ${ }^{62-67}$ The longest term PPI safety and efficacy data in children are for omeprazole, up to 2 years continuous use for maintenance of remission of GORD. ${ }^{69}$ PPIs have been used for up to 11 years' continuous use in children, ${ }^{70}$ but full safety data in this long term group is pending.

While the overall pharmacokinetic profiles of these agents are similar to those in adults, children differ significantly from adults in having an age related enhanced metabolic capacity. ${ }^{71}$ As such, up to about 10 years of age, children often require higher doses on a per $\mathrm{kg}$ basis than adults. Lansoprazole has also been dosed by weight in paediatric studies.

A common error in PPI prescribing in children is underdosing. In fact, if the diagnosis in a child is GORD, and there is poor response to PPI, the likely problem is either that an insufficient dose has been used or the patient is not taking the medication. Another common error in PPI prescribing in children is splitting the total daily dose into twice daily dosing. The optimal administration mode for PPIs is once per day, just before the first meal of the day, when "acid pumps" or "proton pumps" are generated, and can be efficiently blocked. Nevertheless, there are circumstances in which addition of a dose with the evening meal may be indicated. These include severe oesophagitis, peptic stricture, oesophageal motility disorders, persistent nocturnal reflux symptoms, and so-called "atypical" or "extra-oesophageal" GORD-that is, ENT or respiratory manifestations of reflux. ${ }^{72-74}$ It is not necessary, or desirable, to make patients achlorhydric to heal-suppression of acid for part of the day will provide symptomatic relief and healing in most cases.

\section{SUMMARY AND CONCLUSIONS}

The possibility of a surgical cure for GORD - that is, fundoplication, has definite appeal; a curative operation with few adverse effects would be preferable to a lifetime of medication. However, it is an unfortunate irony that those children who have the greatest need for good reflux controlthat is, those with neurological impairment, repaired oesophageal atresia, and chronic lung disease, have underlying pathophysiological mechanisms that lead to wrap failure. Prematurity and early operation in the first year of life are other risk factors for failure. However, even in children and adults without these major underlying disorders, surgery has high failure rates. And in those few surgical studies in which postoperative objective testing is reported, much higher rates of failure and morbidity of fundoplication are shown. 
Most published results of significant morbidity including failure, and mortality, come from among the most experienced centres in each country, and likely show the best outcomes available, so results across the board may be even worse. Studies that claim excellent outcomes for antireflux surgery in children are largely based on casual postoperative assessments, with few if any objective outcome measures. Death also occurs, related to the procedure, even sometimes in those with no underlying disease. Failed surgery is often treated with a second or third operation, and repeat operations have higher morbidity and failure..21 272931

As stated by Hogan and Shaker, regarding adults: ${ }^{75}$ "...operation should not be first-line therapy for the majority of GORD patients. An oesophagus disabled by an inappropriate or dysfunctional fundoplication wrap is a terrible price to pay for control of acid reflux". One might add that mortality is clearly an unjustifiable price to pay when medical therapy might work-the treatment should not be worse than the disease. Along these lines, even in the pre-PPI era, some surgeons concluded that, in NI children, "The use of fundoplication to...improve outcome with an acceptably low risk...does not appear to be established" ${ }^{\prime 7}{ }^{76}$ Other paediatric surgeons share the concern. ${ }^{23} 24313237$

Laparoscopic surgery is not a panacea-while it allows for shorter hospital stays and fewer immediate complications, disabling dysphagia and failure rates may be higher than with open surgery. The ability to perform the operation laparoscopically should not widen the indications for surgery, nor lessen the rigour of diagnostic workup.

The advent of data showing safe, effective use of PPIs in children has revolutionised the therapeutic landscape. However, the medical approach may take some time and patience, to ensure an adequate dose, an appropriate dosing regimen, an age appropriate formulation, and understanding on the part of the family and child, to optimise compliance. In addition, not all GORD is amenable to PPI therapy. Such an example is recurrent/life threatening aspiration due to reflux, though this is a difficult diagnosis to make and it is not clear how common a circumstance it is.

Many children undergo surgery without a firm diagnosis. It is even possible that the good outcomes reported, especially in some "normal" children, are due to the fact that they never had chronic reflux in the first place, so that even if the fundoplication failed, it might not matter. The point is, surgical outcome data cannot be reliable if the diagnosis of chronic relapsing GORD has not been nailed down.

Many children come to surgery without having failed a thorough trial of optimised medical therapy. Candidates for surgery or long term PPI should undergo appropriate diagnostic investigation, followed by trials on and off adequate dose PPIs, to ensure that reflux is the diagnosis, and that it is chronic and relapsing. In other words, patients must "earn" long term PPI or surgery. In adults, a predictor of a good surgical outcome is the response of typical symptoms of reflux to PPI therapy. ${ }^{49}$ Therefore, a trial of optimised medical treatment with PPIs serves a corroborative diagnostic purpose, in addition to providing what the patient wants-prompt symptom relief.

At our institution, the only tertiary children's hospital for the Province of British Columbia (population $\sim 4$ million), use of this approach in conjunction with our paediatric surgical colleagues, has resulted in our rates of antireflux surgery decreasing from 40-50 new fundoplications per year in the late 1980s and early 1990s, to 3-5 such operations per year since 1995 (personal communication, Dr GK Blair, Dept of Surgery, BC Children's Hospital). Patients considered for surgery have had thorough diagnostic testing and trials on and off PPIs.
Given the availability of highly effective and safe medical therapy for GORD, and disappointing surgical outcomes, the current widespread use of antireflux surgery, laparoscopic or open, is difficult to justify. Surgery may work well in the long term in selected patients, but despite four decades of different surgical techniques and experience, there are few published paediatric data that show this.

More data on outcomes, especially in "normal" children, can be obtained only with prospective studies which include objective testing of patients preoperatively to verify the diagnosis of GO reflux disease, documentation of the details of optimised medical therapy that might have failed and why, and further testing in the months and years postoperatively. In addition, longer term paediatric safety data for PPIs is required. More data regarding how better to select those patients who may have good surgical outcomes are needed.

When we refer a child for antireflux surgery, it seems reasonable to expect a safe outcome, with a cure of reflux that is lifelong, or lasts at least a decade or two-that is, a long term freedom from symptoms and medications. While some patients may do well with surgery, serious complications do occur, and failure rates are high, even within the first few years. We therefore need to fully inform families of the real pros and cons of surgery versus current medical options.

Competing interests: E Hassall has received grant support from AstraZeneca in the past, and has served as a paid consultant to AstraZeneca and TAP Pharmaceutical Products Inc.

\section{REFERENCES}

1 Nelson SP, Chen EH, Syniar GM, et al. Prevalence of symptoms of gastroesophageal reflux during infancy. A pediatric practice-based survey. Pediatric Practice Research Group. Arch Pediatr Adolesc Med 1997; 151:569-72.

2 Gupta S, Hassall E, Chiu Y-L, et al. Presenting symptoms of non-erosive and erosive esophagitis in children and adolescents. Gastroenterology 2001; 120:A422.

3 El-Serag HB, Gilger MA, Carter J, et al. Childhood GERD is a risk factor for GERD in adolescents and young adults. Am J Gastroenterol 2004; 100:806-12.

4 Rudolph CD, Mazur U, Liptak SG, et al. Guidelines for evaluation and treatment of gastroesophageal reflux in infants and children: recommendations of the North American Society for Pediatric Gastroenterology and Nutrition. J Pediatr Gastroenterol Nutr 2001;32:S1-31.

5 Hassall E. Barrett's esophagus: new definitions and approaches in children. J Pediatr Gastroenterol Nutr 1993;16:345-64.

6 Hassall E. Co-morbidities in childhood Barrett's esophagus. J Pediatr Gastroenterol Nutr 1997;25:255-60.

7 Hassall E. Decisions in diagnosing and managing chronic gastroesophageal reflux. J Pediatr 2005; 146(suppl 1):S3-12.

8 Di Lorenzo C, Flores A, Hyman PE. Intestinal motility in symptomatic children with fundoplication. J Pediatr Gastroenterol Nutr 1991;12:169-73.

9 Di Lorenzo C, Orenstein S. Fundoplication: friend or foe? J Pediatr Gastroenterol Nutr 2002;34:117-24.

10 Vandenplas $Y$, Hassall E. Mechanisms of gastroesophageal reflux and gastroesophageal reflux disease. J Pediatr Gastroenterol Nutr 2002;35:119-36.

11 Hassall E. Wrap session: is the Nissen slipping? Can medical treatment replace surgery for severe gastroesophageal reflux disease in children? Am J Gastroenterol 1995;90:1212-20.

12 Carre I, Johnston BT, Thomas PS, et al. Familial hiatal hernia in a large five generation family confirming true autosomal dominant inheritance. Gut 1999;45:649-52.

13 Murray JA, Camilleri M. The fall and rise of the hiatal hernia. Gastroenterology 2000;119:1779-81.

14 Hassall E. Esophageal biopsy in children-essential, valuable, or a waste of time? It all depends. J Pediatr Gastroenterol Nutr. In press.

15 Nissen R. Gastropexy and fundoplication in surgical treatment of hiatal hernia. Am J Dig Dis 1961;6:954-61.

16 Filler RM, Gross RE. Esophageal hiatus hernia in infants and children. J Thorac Cardiovasc Surg 1964;47:551-65.

17 Cahill JL, Aberdeen E, Waterston DJ. Results of surgical treatment of esophageal hiatal hernia in infancy. Surgery 1969;66:597-602.

18 Curci MR, Dibbins AW. Problems associated with Nissen fundoplication following tracheoesophageal fistula and esophageal atresia repair. Arch Surg 1988;123:618-20.

19 Lindahl H, Rintala R, Louhimo I. Failure of the Nissen fundoplication to control gastroesophageal reflux in esophageal atresia patients. J Pediatr Surg 1989;24:985-7. 
20 Pearl RH, Robie DK, Ein SH, et al. Complications of gastroesophageal antireflux surgery in neurologically impaired versus neurologically normal children. J Pediatr Surg 1990;25:1169-73.

21 Caniano DA Ginn-Pease ME, King DR. The failed antireflux procedure: analysis of risk factors and morbidity. J Pediatr Surg 1990;25:1022-6.

22 Martinez DA, Ginn-Pease ME, Caniano DA. Sequelae of antireflux surgery in profoundly disabled children. J Pediatr Surg 1992;27:267-73.

23 Martinez DA, Ginn-Pease ME, Caniano DA. Recognition of recurrent gastroesophageal reflux following antireflux surgery in the neurologically disabled child: high index of suspicion and definitive evaluation. J Pediatr Surg 1992;27:983-90.

24 Smith CD, Biemann Othersen H, Gogan NJ, et al. Nissen fundoplication in children with profound neurologic disability. High risks and unmet goals. Ann Surg 1992;215:654-9.

25 Ashcraft KW. Gastroesophageal reflux. In: Ashcraft KW, Holder TM, eds. Pediatric surgery. Philadelphia: WB Saunders Company, 1993:270-88.

26 Spitz L, Roth K, Kiely EM, et al. Operation for gastro-oesophageal reflux associated with severe mental retardation. Arch Dis Child 1993;68:347-51.

27 Wheatley MJ, Coran AG, Wesley JR. Efficacy of the Nissen fundoplication in the management of gastroesophageal reflux following esophageal atresia repair. J Pediatr Surg 1993;28:53-5.

28 Taylor LA, Weiner T, Lacey SR, et al. Chronic lung disease is the leading risk factor correlating with the failure (wrap disruption) of antireflux procedures in children. J Pediatr Surg 1994;29:161-6.

29 Dalla Vecchia LK, Grosfeld JL, West KW, et al. Reoperation after Nissen fundoplication in children with gastroesophageal reflux. Ann Surg 1997;226:315-23.

30 Fonkalsrud EW, Ashcraft KW, Coran AG, et al. The surgical management of gastroesophageal reflux in children: a combined hospital study of 7467 patients. Pediatrics 1998;101:419-22.

31 Kimber C, Kiely EM, Spitz L. The failure rate of surgery for gastroesophageal reflux. J Pediatr Surg 1998;33:64-6.

32 Rubiak R, Spitz L, Kiely EM, et al. Effectiveness of fundoplication in early infancy. J Pediatr Surg 1999;34:295-9.

33 Van der Zee DC, Arends NJ, Bax NM. The value of 24-hr pH study in evaluating the results of laparoscopic antireflux surgery in children. Surg Endosc 1999;13:918-21.

34 Esposito C, Montupet P, Amici G, et al. Complications of laparoscopic antireflux surgery in childhood. Surg Endosc 2000;14:622-4.

35 Allal H, Captier G, Lopez M, et al. Evaluation of 142 consecutive laparoscopic fundoplications in children: effects of the learning curve and technical choice. J Pediatr Surg 2001;36:921-6.

36 Kawahara H, Nakajima K, Yagi M, et al. Mechanisms responsible for recurrent gastroesophageal reflux in neurologically impaired children who underwent laparoscopic Nissen fundoplication. Surg Endosc 2002; 16:767-71.

37 Kawahara H, Okuyama H, Kubota A, et al. Can laparoscopic antireflux surgery improve the quality of life in children with neurologic and neuromuscular handicaps? J Pediatr Surg 2004;39:1761-4.

38 Gilger MA, Yeh C, Chiang J, et al. Outcomes of surgical fundoplication in children. Clin Gastroenterol Hepatol 2004;2:978-84

39 Gibbons TE, Stockwell JA, Kreh RP, et al. Population-based epidemiological survey of gastroesophageal reflux disease in hospitalized US children. Gastroenterology 2001;120:A419.

40 Gold BD. Outcomes of pediatric gastroesophageal reflux disease: in the first year of life, in childhood, and in adults. J Pediatr Gastroenterol Nutr 2003;37:S33-9.

41 Diaz DM, Gibbons TE, Heiss K, et al. Antireflux surgery outcomes in pediatric gastroesophageal reflux disease. Am J Gastroenterol. In press.

42 Carlson MA, Frantzides CT. Complications and results of primary minimally invasive antireflux procedures: a review of 10,735 reported cases. Am Coll Surg 2001; 193:428-39.

43 Lundell L. Complications after anti-reflux surgery. Best Pract Res Clin Gastroenterol 2004;18:935-45.

44 Harnsberger JK, Corey JJ, Johnson DG, et al. Long-term follow-up of surgery for gastroesophageal reflux in infants and children. J Pediatr 1983; 102:505-8

45 Bais JE, Bartelsman FJ, Bonjer HJ, et al. Laparoscopic or conventional Nissen fundoplication for gastroesophageal reflux disease: randomised clinical trial. Lancet 2000;355:170-4.

46 Deurloo JA, Ekkelkamp S, Bartelsman JFWM, et al. Gastroesophageal reflux: prevalence in adults older than $28 \mathrm{yrs}$ after correction of esophageal atresia. Ann Surg 2003;238:686-9.

47 Rothenberg SS. Experience with 220 consecutive laparoscopic Nissen fundoplications in infants and children. J Pediatr Surg 1998;33:274-8.
48 Vakil N, Shaw M, Kirby R. Clinical effectiveness of laparoscopic fundoplication in a U.S. community. Am J Med 2003;1 14:1-5.

49 Jackson PG, Gleiber MA, Askari R, et al. Predictors of outcome in 100 consecutive laparoscopic antireflux procedures. Am J Surg 2001;181:231-5.

50 Spechler SJ, Lee E, Ahnen D, et al. Long-term outcome of medical and surgical therapies for gastroesophageal reflux disease. Follow-up of a randomized controlled trial. JAMA 2001;285:2331-8.

51 Sullivan EM, Pelletier EM, Richter JE. Use of acid reduction therapy and medical costs among medically vs. surgically managed GERD patients. Am J Gastroenterol 2002;97:S239.

52 Perdikis G, Hinder RA, Lund RJ, et al. Laparoscopic Nissen fundoplication: where do we stand? Surg Laparosc Endosc 1997;7:17-21.

53 Rantanen TK, Salo JA, Sipponen JT. Fatal and life-threatening complications in antireflux surgery: analysis of 5,502 operations. Br J Surg 1999;86:1573-7.

54 Watson DI, Baigrie RJ, Jaimeson GG. A learning curve for laparoscopic fundoplication. Definable, avoidable, or a waste of time? Ann Surg 1996:224:198-203

55 Luostarinen MES, Isolauri JO. Surgical experience improves the long-term results of Nissen fundoplication. Scand J Gastroenterol 1999;34:1 17-20.

56 Marks RD, Richter JE, Rizzo J, et al. Omeprazole versus H2-receptor antagonists in treating patients with peptic stricture and esophagitis. Gastroenterology 1994;106:907-15.

57 Huang J-Q, Hunt RH. Meta-analysis of comparative trials for healing erosive esophagitis with proton pump inhibitors and $\mathrm{H} 2$-receptor antagonists. Gastroenterology 1998;114:A154.

58 Huang JQ, Hunt $\mathrm{RH}$. $\mathrm{pH}$, healing rate, and symptom relief in patients with GERD. Yale J Biol Med 1999;72:181-94.

59 Champion GL, Richter JE, Vaezi MF, et al. Duodenogastroesophageal reflux: relationship to $\mathrm{pH}$ and importance in Barrett's esophagus. Gastroenterology 1994; 107:747-54.

60 Nwokolo CU, Smith JT, Gavey C, et al. Tolerance during 29 days of conventional dosing with cimetidine, nizatidine, famotidine or ranitidine. Aliment Pharmacol Ther 1990;4(suppl 1):29-45.

61 Wilder-Smith CH, Ernst T, Gennoni M, et al. Tolerance to H2-receptor antagonists. Dig Dis Sci 1990;35:976-83.

62 Gunasekaran TS, Hassall E. Efficacy and safety of omeprazole for severe gastroesophageal reflux in children. J Pediatr 1993;123:148-54.

63 Hassall E, Israel DM, Shepherd R, and the International Pediatric Omeprazole Study Group, et al. Omeprazole for treatment of chronic erosive esophagitis in children: a multicenter study of efficacy, safety, tolerability and dose requirements. J Pediatr 2000;137:800-7.

64 Israel DM, Hassall E. Omeprazole and other proton pump inhibitors: pharmacology, efficacy and safety, with special reference to use in children. J Pediatr Gastroenterol Nutr 1998;27:568-79.

65 Tolia V, Ferry G, Gunasekaran T, et al. Efficacy of lansoprazole in the treatment of gastroesophageal reflux disease in children. J Pediatr Gastroenterol Nutr 2002;35:S308-18.

66 Gunasekaran T, Gupta S, Gremse D, et al. Lansoprazole in adolescents with gastroesophageal reflux disease. Pharmacokinetics, pharmacodynamics, symptom relief efficacy and tolerability. J Pediatr Gastroenterol Nutr 2002;35(suppl 4):S327-35.

67 Fiedorek S, Tolia V, Huang B, et al. Efficacy and safety of lansoprazole in adolescents with gastroesophageal reflux disease. J Pediatr Gastroenterol Nutr 2005;40:319-27.

68 Klinkenberg-Knol EC, Nelis F, Dent J, et al. Long-term omeprazole treatment in resistant gastroesophageal reflux disease: efficacy, safety, and influence on gastric mucosa. Gastroenterology 2000;1 18:661-9.

69 Hassall E, for the International Pediatric Omeprazole Study Group. Omeprazole for maintenance therapy of erosive esophagitis in children. Gastroenterology 2000;118:A658.

70 Hassall E, El-Serag H, Kerr W. Continuous use of proton pump inhibitors (PPI) in children up to 11 yrs duration. Gastroenterology 2005; 128:A526.

71 Andersson T, Hassall E, Lundborg P, et al. Pharmacokinetics of orally administered omeprazole in children. International Pediatric Omeprazole Pharmacokinetic Group. Am J Gastroenterol 2000;95:3101-6.

72 Ramakrishnan A, Katz PO. Pharmacologic management of gastroesophageal reflux disease. Curr Treat Options Gastroenterol 2002;5:301-10.

73 Wong RK, Hanson DG, Waring PJ, et al. ENT manifestations of gastroesophageal reflux. Am J Gastroenterol 2000;95(suppl 8):S15-22.

74 Harding SM, Sontag SJ. Asthma and gastroesophageal reflux. Am J Gastroenterol 2000;95(suppl 8):S23-32.

75 Hogan WJ, Shaker R. Life after antireflux surgery. Am J Med 2000;108(4A): 181S-191S.

76 Johnson DG. Current thinking on the role of surgery in gastroesophagea reflux. Pediatr Clin N Am 1985;32:1165-79. 